\title{
Annuitization and Retirement Timing Decisions
}

\author{
Zhen Shi* \\ Tilburg University
}

August 25, 2008

\begin{abstract}
This paper analyzes retirement timing decisions of DC pension plan members. In this paper the optimal annuitization timing decision is incorporated into the retirement timing decision. I first develop a retirement decision model and generate a forward looking retirement likelihood measure from this model. This measure describes the probability that an individual will retire within the next few years. In the model, the individual obtains utility from leisure, labor income before retirement and pension benefit after retirement. The DC pension benefit is the income from the annuity which is bought at the optimal time. The retirement likelihood measure is then tested with the English Longitudinal Study of Ageing (ELSA) data. From investigating the retirement decisions of the sample members in the second wave of ELSA, I conclude that the retirement likelihood measure is a good predictor of actual retirement decisions.
\end{abstract}

Keywords: Retirement, Annuitization, Optimal Stopping Time

JEL Classification Codes: J26, G12

${ }^{*}$ I thank Rik Frehen, Kai Li, Theo Nijman, Frank de Jong, Roel Mehlkopf, Bertrand Melenberg, Eytan Sheshinski, Jonathan Skinner, Bas Werker and seminar participants at Tilburg University, FMA European Meeting Doctoral Student Consortium (Prague) and Netspar Workshop in Den Haag for useful comments and discussions.

${ }^{\dagger}$ CentER, Netspar, and TILEC, Department of Finance, Tilburg University, Warandelaan 2, P.O. Box 90153, 5000 LE, Tilburg, the Netherlands. Email: z.shi@uvt.nl. 


\section{Introduction}

In recent years, there has been a significant shift from Defined Benefit (DB) to Defined Contribution (DC) pension plans in a number of countries, including the U.S., the U.K. and Australia. In the U.S., the number of DB plans has declined sharply in recent years, from 112,208 in 1985 to about 29,600 in 2004 (FDIC 2006). In the U.K., DC plans started widely about two decades ago. At 2002, approximately a third of pension schemes in the U.K. are DC and the trend away from DB funds is expected to accelerate in coming years (Ross and Wills 2002). This shift makes it increasingly interesting to understand determinants of DC pension plan participants' retirement decisions.

Retirement decisions of individuals with DC plans are influenced jointly by many factors, for example, expected and realized investment returns, the individuals' risk aversion, the mortality rate, the subjective valuation of leisure, the labor income and its expected growth rate. DC pension plans generally provide benefit in the form of a lump-sum payment. In some countries, for example, the U.S., there are no obligations to annuitize DC wealth, while in others, for example, the U.K., there are obligations to do so. The seminal paper of Yaari (1965) argues that, in the absence of bequest motive, all retirement wealth should be annuitized. There are two reasons supporting this view. One is that without annuitization there is a risk that the retirees might consume too much so that they will exhaust their retirement resource before they die. The other one is that some retirees might consume too less while they are alive. These individuals could have consumed more to have better life quality. Thus, an important part of annual DC pension income should be annuity income, especially in the countries, like the U.K., where there are obligations to annuitize DC wealth.

In reality, individuals with DC plans do not have to annuitize their DC wealth immediately after retirement. The freedom in choosing the annuitization time allows the individuals to benefit from better financial market performance after retirement. Therefore it should have a large impact on the retirement timing. Without this freedom, it would be better for the individuals to retire when the financial market performance is favorable. However, with this freedom, the individuals does not have to wait for the good financial market performance. It could be optimal for the individuals to retire even when the financial market performance is sluggish because they could continue investing their DC wealth in the financial market after retirement and annuitize the DC wealth when the market performs better. The decision to retire is actually a decision to exercise a compound real option optimally. Once the individual retires, he gets the option to annuitize his pension wealth. The optimal retirement decision depends on the expected outcome 
of the annuitization option.

This paper aims to analyze retirement timing decisions of DC pension plan participants, taking into account the optimal annuitization timing decision. To do so, I will first set up a retirement decision model and develop a forward looking retirement likelihood measure from this model. The retirement likelihood measure describes the probability that an individual will retire within the next few years. In the model, the individual obtains utility from leisure, labor income before retirement and pension benefit after retirement. The DC pension benefit is the income from the annuity which is bought at the optimal annuitization timing.

The retirement likelihood measure is then tested with the English Longitudinal Study of Ageing (ELSA) data. The most important reason why I choose U.K. data is that there is an obligation to annuitize pension wealth before age 75. ELSA is a biannual panel survey among those aged 50 and over (and their younger partners) living in private households in England. For all the individuals who are full-time employed in the wave 1 interviews (conducted in 2002-3), the probabilities of retiring by wave 2 interviews (conducted in 2004-5) are evaluated based only on the information available at wave 1 interviews. The model predictions are compared with the actual retirement ratios and the predictions implied by a Probit model where age, gender, education level and DC wealth are explanatory variables used to explain the retirement decisions reported at the wave 2 interviews. The performance of the retirement likelihood measure, in terms of the correlations with the actual retirement ratios and the Mean Square Errors, are comparable to the performance of the Probit regression. This result gives strong support to the option model setup in this paper because the prediction from the option model is out of sample while the prediction from the Probit regression is in sample.

This paper is related to the literature focusing on the determinants of retirement decision. The first line of research in this area has investigated the retirement incentives of DB pension plan participants. The seminal paper by Stock and Wise (1990) presented an option value model to describe the retirement decision of DB plan participants. Their model is very close in spirit to the stochastic dynamic programming model of Rust (1987). Stock and Wise (1990) applied their model to data from a large company. They found that their model could explain very well the actual retirement ratios in that company. They argue that pension wealth is a significant determinant of the retirement probability. Samwick (1998) applied the option model to a national-wide dataset. His research confirmed and strengthened the results of Stock and Wise (1990). Sundaresan and Zapatero (1997) linked the option value to the lifetime marginal productivity schedule which, 
given their assumption, is increasing at the beginning of the working life and then starts decreasing. They argue that people will retire when the ratio of DB pension benefit and the current wage reaches certain threshold value. This paper extends the option value model of Stock and Wise (1990) to the DC plan participants' retirement decision.

The second line of research focuses on differences between impacts of DB and DC pension plans on the retirement decision and pension income. Friedberg and Webb (2005) studied the Health and Retirement Survey data and found that workers with DC plans are retiring significantly later compared with the ones with DB scheme. Samwick and Skinner (1998) investigated whether DC plans, compared to DB plans, are adequate in providing for a comfortable retirement pension. Their results show that DC plans can strengthen the financial security of the retirees.

The third line of research looks at the interactions among wealth, investment strategies and the retirement decision. Gustman and Steinmeier (2002) and Coronado and Perozek (2003) studied the effect of a positive shock in household wealth including private savings and savings through DC accounts on household members' retirement decision making. These two papers investigated the period in the late 1990s when the stock market was booming in the U.S.. Both papers found that the extraordinary high returns in the stock market increased retirement in the United States. Lachance (2003), Choi and Shim (2006), Farhi and Panageas (2007) and Liu and Neis (2002) studied the issue of retirement decision and its implication on the investment choice. Choi and Shim (2006) show that the individual consumes less and invests more in risky assets when he has an option to retire than he should in the absence of such an option. Farhi and Penagear (2007) find that investing for early retirement tends to increase savings and reduce an agent's effective relative risk aversion, thus increasing his stock market exposure.

This paper is also related to the literature on optimal annuitization timing. The literature in this topic is relatively small but growing. Milevsky and Young (2002) developed a normative model of when the individuals should annuitize their wealth. Their model was built on Merton (1971) and solved by the standard continuous-time technology. Milevsky and Young (2007) argued that in the US annuitization prior to age 65-70 was not optimal even in the absence of any bequest motives.

The main contribution of this paper is to incorporate the optimal annuitization timing decision into a normative model explaining the optimal retirement decision making of DC plan participants. There is no doubt that the annuitization timing has large impact on the size of the DC pension benefit. Therefore, rational individuals with DC plans should take this into account while making their retirement decision. Incorporating the optimal 
annuitization decision making improves the comprehensiveness of a normative model for optimal retirement timing decision. The empirical findings of this paper suggest that in reality at least some individuals recognize the value of the freedom in choosing the annuitization timing and incorporate it into their retirement decision making.

The organization of the paper is as follows. Section 2 gives a brief introduction to the British pension system. Section 3 describes the option value model. Second 4 presents the solution method to the model. Second 5 discusses the empirical investigation of the model prediction. Section 6 concludes.

\section{The British Pension System}

The U.K. pension system consists of three main pillars. The first pillar, known as Basic State Pension (BSP), is a mandatory, flat rate state pension ${ }^{1}$. The second pillar system is provided by the state, employers and private sector financial institutions. In the second pillar, the employees have considerable choices over the type of pension that they can accumulate. The main choices are between: (1) an earnings-related state pension plan ${ }^{2}$; (2) an occupational DB plan provided by employers and (3) an occupational DC pension plan. The state pension plan offers a pension that is low relative to average earnings, but is fully indexed to prices after retirement. The occupational DB plan offers a relatively high level of pension to the employees who spend most of their working time with the same employer, but provides poor transfer values between plans on changing jobs. The occupational DC pension plan is fully portable, but the pension income depends on uncertain investment returns (see Blake 2003). The second pillar state pension is by default compulsory to all the employees who earn above a lower threshold set by the state. But individuals are able to contract out of the second pillar state pension into an occupational pension scheme provided that the latter is at least as generous as the second-pillar state pension. The third pillar consists of voluntary private pension plans ${ }^{3}$. The third pillar pension arrangements are usually of DC type.

\footnotetext{
${ }^{1}$ The BSP is funded on a pay-as-you-go basis. It is a flat rate benefit. Individuals are entitled to at least some part of the BSP if they have made National Insurance (NI) contributions for at least $25 \%$ of their working lives. The BSP benefit in 2006/7 is about $£ 85$ per week (Department of Work and Pensions). This benefit is indexed to inflation (Clark and Emmerson 2003).

${ }^{2}$ The second pillar state pension plan was called State Earnings-Related Pension Scheme (SERPS) and replaced by State Second Pension (S2P) in 2002. The second pillar state pension plans are of DB nature (Cocco and Lopes 2004). Both the first and second pillar state pensions are paid by the Department of Pension and Working once the retiree reaches his State Pension Age (SPA). Currently the State Pension Age is 65 for men and 60 for women. By 2020, the SPA for woman will increase gradually to 65 .

${ }^{3}$ Employers and individuals can also make additional contributions to a private pension. The state supports the savings in private pension plans through tax relief (see Clark and Emmerson 2003).
} 
In the U.K., the DC plan participants do not have to annuitize their DC wealth immediately at the retirement date. Up to one-quarter of the value of a pension fund can be taken as a lump sum, but three-quarters must be annuitized before the age of 75 (Finance Act 1995). The obligation to annuitize DC wealth and the freedom in choosing the annuitization time are the most important reasons why U.K. data is selected for the empirical investigation in this paper.

\section{The Model}

The aim of this section is to model the optimal retirement decision of an individual participating in a DC plan, taking into account the optimal annuitization timing. This model will also account for the DB and the state pension plans existing next to the DC pension plan. Currently, we are at time 0 and the individual's current age is $F$, where $50 \leq F<75$. He is working full time at time 0 . He can retire between time $1,2,3, \ldots$ and time $T$ where time $T$ is the time when this person turns 75 years old. The oldest age the individual could reach is assumed to be $T_{\max }$ and $T_{\max }>T$. His current DC wealth is $W_{0}$. The individual does not have to annuitize his retirement wealth immediately after retirement unless he retires at time $T$. If he retires before time $T$, he could annuitize his pension wealth between the retirement date, say $t$, and $T$.

Assume that the individual retires at time $t$, where $t$ could be any time between 1 and $T$ and annuitizes at time $t_{a}$, which could be either at or between time $t$ and $T$. His subsequent pension income, $P\left(t, t_{a}\right)$, consists of annuity income, $A\left(t, t_{a}\right)$, after the individual annuitizes his DC wealth, the amount, $Q\left(t, t_{a}\right)$, withdrawn from his DC wealth before annuitization, the income from current and past DB plans, $C D B(t)$ and $P D B(t)$, and the state pension, $S P(t)$, that is,

$$
\begin{aligned}
P\left(t, t_{a}\right)_{j} & =\left\{\begin{array}{l}
A\left(t, t_{a}\right)+C D B(t)_{j}+P D B(t)_{j}+S P(t)_{j}, \quad \text { for } T_{\max } \geq j \geq t_{a}, \\
Q\left(t, t_{a}\right)+C D B(t)_{j}+P D B(t)_{j}+S P(t)_{j}, \quad \text { for } t_{a}>j \geq 1,
\end{array}\right. \\
& =D C\left(t, t_{a}\right)+C D B(t)_{j}+P D B(t)_{j}+S P(t)_{j},
\end{aligned}
$$

where

$$
D C\left(t, t_{a}\right)=\left\{\begin{array}{lc}
A\left(t, t_{a}\right), & \text { for } T_{\max } \geq j \geq t_{a} \\
Q\left(t, t_{a}\right), & \text { for } t_{a}>j \geq 1
\end{array} .\right.
$$

For any given pairs of $t$ and $t_{a}, Q\left(t, t_{a}\right)$ is constant over time $\left(t, t_{a}\right)$ and $A\left(t, t_{a}\right)$ is constant over time $\left(t_{a}, T\right)$. The $\mathrm{DB}$ and state pension benefits, $C D B(t)_{j}, P D B(t)_{j}$ and $S P(t)_{j}$, are indexed to inflation after retirement. The pension benefits, $A\left(t, t_{a}\right)$, $Q\left(t, t_{a}\right), C D B(t), P D B(t)$ and $S P(t)$ will be discussed below in more detail. 


\section{The Financial Market}

In this section, the asset universe available to the DC pension plan member for investment purposes will be introduced. There are one stock index and one bond index available in the financial market. The diffusion processes of the short term interest rate and the stock index are as follows,

$$
\begin{aligned}
d r_{t} & =\kappa_{r}\left(\bar{r}-r_{t}\right) d t+\sigma_{r} d Z_{1 t} \\
d S_{t} & =\left(r_{t}+\lambda_{s} \sigma_{s}\right) S_{t} d t+\sigma_{s} S_{t} d Z_{2 t}
\end{aligned}
$$

where $\lambda_{s}$ is the Sharpe Ratio of stock price, and $\sigma_{\lambda}, \kappa_{r}, \bar{r}, \sigma_{r}, \lambda_{s}, \sigma_{s}$ are constants. $Z_{1}$ and $Z_{2}$ are two independent standard Brownian Motions supported by a probability space $(\Omega, \mathcal{F}, P)$ over the finite time horizon $(0, T)$. All stochastic processes introduced in this paper are assumed to be measurable with respect to the augmented filtration $\left\{\mathcal{F}_{t}: t \in(0, T)\right\}$.

From the Vasicek model, we can get the price of the zero-coupon bond at time $t$ with time to maturity $h$

$$
B_{t}^{(h)}=e^{-a(h)-b(h) r_{t}}
$$

where

$$
\begin{gathered}
a(h)=\left(\bar{r}-\frac{\lambda_{r} \sigma_{r}}{\kappa}-\frac{\sigma_{r}^{2}}{2 \kappa^{2}}\right)(h-b(h))+\frac{\sigma_{r}^{2}}{4 \kappa} b(h)^{2}, \\
b(h)=\frac{1}{\kappa}\left(1-e^{-\kappa h}\right),
\end{gathered}
$$

and $\lambda_{r}$ is the interest rate price of risk. The yield of a zero-coupon bond with time to maturity $h, Y(h)$, is

$$
Y(h)=\frac{a(h)+b(h) r_{t}}{h}
$$

By Ito's lemma, the dynamics of any arbitrary bond prices can be described by

$$
d B_{t}=B_{t}\left[\left(r_{t}+\lambda_{r} \sigma_{B, t}\right) d t+\sigma_{B, t} d Z_{1 t}\right]
$$

where $\sigma_{B, t}=\sigma_{r} D(r, t)$ and $D(r, t)=-\frac{d B_{t}}{d r} \frac{1}{B_{t}}$ is the elasticity of the bond price with respect to the short interest rate. The elasticity is referred to as the duration of the interest rate contingent claim. Following Munk, et al (2003), it is assumed that the bond available for the investor has a constant duration $D>0$. This can be thought of as reflecting the duration of the aggregate portfolio of bonds outstanding, or a bond index, where bonds that expire are always substituted with new longer term bonds. 


\section{The DC Income}

As we have seen before, the DC income, $D C\left(t, t_{a}\right)$, consists of the amount the individual withdraw before annuitization, $Q\left(t, t_{a}\right)$, and annuity income after the annuitization, $A\left(t, t_{a}\right)$. The DC income is jointly affected among other factors by the investment returns, the amount of contributions made to the DC plan and the annuity rates.

Let $W\left(t, t_{a}\right)_{j}$ denote the individual's DC portfolio wealth at time $j, j \in\left[t, t_{a}\right]$, if the individual retires at time $t$ and annuitizes at time $t_{a}$. Assume that the total amount of contributions paid by the individual and his employer to the DC plan is $C$ per year. After retirement, the individual will withdraw $Q\left(t, t_{a}\right)$ per year from his DC wealth before annuitization. A fraction $\alpha$ of his DC assets is invested in the stock index and $1-\alpha$ in the bond index. As in Samwick and Skinner (2003), the investment portfolio will be rebalanced annually to keep the weight of the stock and bond at $\alpha$ and $1-\alpha$. The optimal annuitization and retirement dates will be described below. For every possible combination of retirement and annuitization dates, that is, $0 \leq t \leq T$ and $t \leq t_{a} \leq T$, the individual's DC wealth can be described as follows

$$
W\left(t, t_{a}\right)_{j}=\left\{\begin{array}{cc}
\left(\frac{\alpha \times\left(W\left(t, t_{a}\right)_{j-1}+C\right)}{S_{j-1}}\right) S_{j}+\left(\frac{(1-\alpha) \times\left(W\left(t, t_{a}\right)_{j-1}+C\right)}{B_{j-1}}\right) B_{j}, & 1 \leq j \leq t . \\
\left(\frac{\alpha \times\left(W\left(t, t_{a}\right)_{j-1}-Q\left(t, t_{a}\right)\right)}{S_{j-1}}\right) S_{j}+\left(\frac{(1-\alpha) \times\left(W\left(t, t_{a}\right)_{j-1}-Q\left(t, t_{a}\right)\right)}{B_{j-1}}\right) B_{j}, & t<j \leq t_{a} .
\end{array}\right.
$$

The upper part of equation (7) describes the wealth process before retirement and the lower part describes the wealth process after retirement. Before the individual retires, the total amount of DC wealth available for investing is the sum of the previous DC wealth and the new contribution. After the individual retires but before the individual annuitizes his DC wealth, the total amount of DC wealth available for investing is the difference between the previous DC wealth and the amount withdrawn by the individual.

If the individual retires at time $t$ and annuitizes his DC wealth at time $t_{a}$, the annuity income, $A\left(t, t_{a}\right)$, which he will receive immediately after annuitization until he dies depends, among others, on the term structure and the amount of DC wealth at the annuitization date, $t_{a} . A\left(t, t_{a}\right)$ is determined as follows,

$$
W\left(t, t_{a}\right)_{t_{a}}=A\left(t, t_{a}\right)\left[1+\sum_{j=1}^{T_{\max }-t_{a}}\left(\frac{1}{\left(1+r_{t_{a}}^{(j)}\right)^{j}} \prod_{k=1}^{j} M_{k}\right)\right](1+p) .
$$

In eq.(8), $p$ is a load factor which is greater than or equal to zero, obtaining a measure 
of the "money's worth" of the annuity. If the load factor is zero, then the annuity contract is actuarially fair and the "money's worth" equals one. Empirical evidence by Mitchell et. al. (1999) illustrates that the load factor varies between $8 \%$ and $20 \%$ depending on different assumptions about discounting and mortality tables. $M_{k}$ denote the probability that the individual is alive at time $\mathrm{k}$, conditional on being alive at time $\mathrm{k}-1$ and $M_{1} \equiv 1$. $r_{t_{a}}^{(j)}$ is the j-year interest rate at the time of annuitization.

I assume that the amount, $Q\left(t, t_{a}\right)$, the individual withdraws after retirement but before annuitization equals the amount of annuity income he could get if he annuitizes immediately after retirement, that is,

$$
Q\left(t, t_{a}\right)=A(t, t)
$$

The DB and state pension incomes are introduced in the following part of this section.

\section{The DB and State Pension Income}

If the person retires at time $t$, where t could be any time between 1 and $T$, his income from current and past DB plans, $C D B(t)$ and $P D B(t)$, are determined by, among others, the accrual rate, years of membership and labor income, that is,

$$
\begin{aligned}
& C D B(t)=a c c \_ \text {rate } \times n_{t} \times Y_{t} \\
& P D B(t)=a c c \_ \text {rate } \times n_{\text {past }} \times Y_{\text {lastyear }} \times \exp \left(\pi\left(t-t_{\text {lastyear }}\right)\right), \text { with } t_{\text {lastyear }}<t(10)
\end{aligned}
$$

where $a c c \_r a t e$ is the accrual rate, $n_{t}$ is the number of membership years in the current DB scheme at time $\mathrm{t}, n_{\text {past }}$ is the number of years in the past DB scheme, $\pi$ is the annual inflation rate, $t_{\text {lastyear }}$ is the last year in the past DB plan, $Y_{\text {lastyear }}$ is the individual's annual gross income during his last year in the past scheme and $Y_{t}$ is the person's annual gross income at time $t$. Thus, the DB plan is of a final salary type and the DB income after retirement is indexed to inflation which is required by law in the U.K. (see Blake 2003). This means if the individual retires at time $t$, his income afterwards is,

$$
\begin{aligned}
& C D B(t)_{j}=C D B(t) \exp (\pi(j-t)), \text { for } j=t \ldots T_{\max } \\
& P D B(t)_{j}=P D B(t) \exp (\pi(j-t)), \text { for } j=t \ldots T_{\max } .
\end{aligned}
$$

The state pension is also indexed to inflation, therefore, we have

$$
S P(t)_{j}=S P(t) \exp (\pi(j-t)), \text { for } j=t \ldots T_{\max } .
$$




\section{The Objective Function}

The utility function is closely related to Stock and Wise (1990). At time 0, the individual is full time employed. The individual can retire between time 1 and T. Looking ahead, he will receive his labor income as long as he keeps working. Once he retires he receives pension income and enjoys the leisure until he dies. At time $t, 1 \leq t \leq T$, if the individual retires, his utility of retirement, $U_{t}$, is the sum of the utility from labor income, pension benefit and leisure, that is,

$$
U_{t}=\sum_{s=1}^{t-1} \exp (\beta(t-s)) \frac{Y_{s}^{1-\gamma}}{1-\gamma}+\sum_{s=t}^{T_{\max }} \exp (\beta(t-s)) \frac{\left(K P\left(t, t_{a}\right)_{s}\right)^{1-\gamma}}{1-\gamma} \prod_{k=t}^{s} M_{k}
$$

where $\beta$ stands for the subjective discount factor and the parameter $K$ takes into account the disutility of work. $Y_{s}$ stands for labor income which is deterministic and $P\left(t, t_{a}\right)_{s}$ is

the pension income which is explained in (1). $\prod_{k=t}^{s} M_{k}$ is the cumulative survival probability from time $t$ to $s$ with $M_{t}=1$. The first term of (12) is the accumulation of the utility from labor income at time $t$ and the second term is the sum of the discounted utility from pension and leisure at time $t$. As in Stock and Wise (1990), the parameter $K$ has two specifications. In the first specification, $K$ is a constant. In the second specification, $K$ is a convex function of current age, $F$, and $K=k_{0}\left(\frac{F}{k_{2}}\right)^{k_{1}}$ where $k_{0}, k_{1}$ and $k_{2}$ are constants. Note that the amount of utility gain from leisure is increasing with the DC wealth level. To adjust for the wealth effect, $K$ is set to be $k_{3} \times k_{0}\left(\frac{F}{k_{2}}\right)^{k_{1}}$ for the individuals with very large DC wealth, where $0<k_{3}<1$.

For each of the possible retirement stopping times, the DB and state pension income is determined by (9), (10) and (11). But as we have seen in Section 3.2, the DC pension income, $D C\left(t, t_{a}\right)$, depends not only on when the individual retires but also on when DC wealth is annuitized. This makes the retirement option a compounded real option. Once the individual retires, he obtains the right to exercise his annuitization option. But the retirement decision depends on the expected outcome of the annuitization option. Therefore, in order to find a solution to (12), we first have to find the optimal annuitization timing and thus, the optimal DC pension income, $P\left(t, t_{a}^{*}\right)$, for all the possible retirement times from year 1, 2, 3 to year $T$. After that, we could attempt to solve for the optimal retirement timing for eq.(12).

The retirement timing decision is an example of optimal stopping problems with fixed horizon. The optimal stopping problem describes the problem of choosing a time to stop a certain action based on sequentially observed random variables in order to maximize 
the expected payoff or utility. A random variable $\tau$ defined on $\Omega$ and taking values in the time set is called a stopping time if the event $\{\tau \leq t\}$ belongs to $\mathcal{F}_{t}$ for all $t \in(1, T)$. In other words, for $\tau$, to be a stopping time, it should be possible to decide whether or not the event $\{\tau \leq t\}$ has occurred based on the knowledge that are known at time t, i.e., the knowledge in the information set $\mathcal{F}_{t}$. The stopping time for retirement decisions is called retirement stopping time. The retirement problem can be formulated as finding an optimal retirement stopping time, $\tau_{r}^{*}$, from all retirement stopping times, $\tau_{r}$, with values in $(1, T)$, that maximizes the expected discounted utility of retirement at time 1 , i.e.,

$$
\sup _{1 \leq \tau_{r} \leq T} E_{1}\left[\exp \left(-\beta\left(\tau_{r}-1\right)\right)\left(\prod_{k=1}^{\tau_{r}} M_{k}\right) U_{\tau_{r}}\right]
$$

where $\prod_{k=1}^{\tau_{r}} M_{k}$ is the cumulative surviving probability from time 1 to $\tau_{r}$ with $M_{1}=1$.

The annuitization timing decision is also an example of optimal stopping problems with fixed horizon. The stopping time for annuitization decisions is called annuitization stopping time. The annuitization time, $\tau_{a}$, must be between retirement time and the deadline for annuitization, that is, $\tau_{a} \in\left(\tau_{r}, T\right)$. The optimal annuitization stopping timing, $\tau_{a}^{*}$, is the stopping time that maximizes the expected discounted utility of pension income at retirement time $\tau_{r}$, with $\tau_{r} \in(1, T)$, that is,

$$
\sup _{\tau_{r} \leq \tau_{a} \leq T} E_{\tau_{r}}\left[\exp \left(-\beta\left(\tau_{a}-\tau_{r}\right)\right) B\left(\tau_{r}, \tau_{a}\right)\right]
$$

where $B\left(\tau_{r}, \tau_{a}\right)=\sum_{s=\tau_{r}}^{T_{\max }} \exp \left(\beta\left(\tau_{a}-s\right)\right)\left(\prod_{k=\tau_{r}}^{s} M_{k}\right) \frac{D C\left(\tau_{r}, \tau_{a}\right)^{1-\gamma}}{1-\gamma}$ and the product, $\exp \left(-\beta\left(\tau_{a}-\right.\right.$ $\left.\left.\tau_{r}\right)\right) \times B\left(\tau_{r}, \tau_{a}\right)$, is the sum of the discounted utility of pension income at retirement time $\tau_{r}$.

\section{Summary of Section 3}

In this section, a theoretical model was set up to explain the retirement decision of an individual with DC pension plan. In the model, the individual obtains utility from labor income, pension benefit and leisure. The annuitization time could be later than the retirement time. The DC pension benefit depends not only on the financial market performance but also on the annuitization timing. In order to find the optimal retirement timing, we first have to find the optimal annuitization stopping time for all the possible retirement times and then, we can use the dynamic programming principle to find the 
optimal retirement time. The detailed solution to the model will be discussed in Section 4.

\section{The Solution Method}

The optimal annuitization and retirement decisions are very similar to the decision of exercising an American option optimally, in the sense that, like the American option, both the retirement and annuitization decisions can be made at any stopping time between the "purchase" date, in our cases, the time when the individual is allowed to retire/annuitize, and the "expiration" date, in our cases, the time when the individual turns 75 years old.

Let $n$ be the "purchase" date of an annuitization option or a retirement option. The optimal annuitization and retirement stopping problems can be stated as

$$
V_{n}=\sup _{n \leq \tau \leq T} E_{n}\left[\exp (-\beta(\tau-n)) Z_{\tau}\right]
$$

where the function $Z(\cdot)=\left(\prod_{k=1}^{\tau} M_{k}\right) U(\cdot)$ for the retirement option, $Z(\cdot)=B(\cdot)$ for the annuitization option, $n=1$ for the retirement option and $n=\tau_{r}$ for the annuitization option.

The standard solution to a optimal stopping problem with finite horizon is to follow the dynamic programming principle (c.f. Peskir and Shiryaev 2006). Let $J_{t}$ be the highest attainable expected utility at time $t$ the individual can achieve if he exercises his option at or later than time $t$, that is,

$$
J_{t}=\sup _{t \leq \tau \leq T} \exp (-\beta(\tau-t)) E\left(Z_{\tau} \mid \mathcal{F}_{t}\right)
$$

Here exercising an option means retiring for the retirement option and annuitizing for the annuitization option. At time $t=T$, the individual has to stop immediately and gains $J_{T}=Z_{T}$. At time $t=T-\Delta t$, where $\Delta t$ stands for very short period of time, he can either stop or continue. If he stops, $\tau=t$ and $J_{T-\Delta t}$ equals to $Z_{T-\Delta t}$, and if he continues, $\tau=T$ and $J_{T-\Delta t}$ equals to $\exp (-\beta \Delta t) E\left(J_{T} \mid \mathcal{F}_{T-\Delta t}\right)$. It follows that if $Z_{T-\Delta t} \geq \exp (-\beta \Delta t) E\left(J_{T} \mid \mathcal{F}_{T-\Delta t}\right)$ then he needs to stop at time $t=T-\Delta t$; otherwise, he needs to continue at time $t=T-\Delta t$. This decision rule reflects the fact that the individual's decision about stopping or continuation at time $t=T-\Delta t$ must be based on the information contained in $\mathcal{F}_{T-\Delta t}$ only. For $t=T-2 \Delta t, \ldots, n$, the considerations are continued analogously. 
The method of backward induction just explained leads to a sequence of random variables, $\left(J_{t}\right)_{n \leq t \leq T}$, defined recursively as follows:

$$
\begin{aligned}
J_{t} & =Z_{T} \text { for } t=T \\
J_{t} & =\max \left(Z_{t}, \exp (-\beta \Delta t) E\left(J_{t+\Delta t} \mid \mathcal{F}_{t}\right)\right) \text { for } t=T-\Delta t, \ldots n .
\end{aligned}
$$

The method also suggests that we consider the following stopping time

$$
\tau_{n}=\min \left\{n \leq k \leq T: J_{k}=Z_{k}\right\}
$$

as a candidate for optimal stopping time for problem (15). Peskir and Shiryaev (2006) proved that $\tau_{n}$ is indeed the optimal stopping time in (15). The proof is provided in Appendix A.

At time $t, t<T$, the value of immediate exercise, $Z_{t}$, is known to the individual. But the value of $\exp (-\beta \Delta t) E\left(J_{t+\Delta t} \mid \mathcal{F}_{t}\right)$ is still unknown. The key to solve the optimal stopping problem (15) is therefore, to evaluate the conditional expectations, $\exp (-\beta \Delta t) E\left(J_{t+\Delta t} \mid \mathcal{F}_{t}\right)$ for $t=T-\Delta t, \ldots n$. Least Square Monte Carlo (LSM) valuation algorithm developed by Longstaff and Schwartz (2001) is adopted to approximate $E\left(J_{t+\Delta t} \mid \mathcal{F}_{t}\right)$ and to solve optimal stopping problem numerically.

\section{The Least Square Monte Carlo (LSM) Algorithm}

The objective of the LSM algorithm is to provide a pathwise approximation to the optimal stopping rules. It is assumed that the option can only be exercised and considered at a finite number of discrete times, $n, \ldots, t, t+\Delta t, \ldots T$. For each exercise date, $n, \ldots T, N$ paths (scenarios) of stock prices and short-term interest rates are simulated.

The LSM algorithm follows the standard backward induction method as described previously. At the final expiration date, $T$, the option has to be exercised, the individual gets $Z_{T, i}$, where $i$ stands for a simulated path and $i=1,2, \ldots N$. At exercise dates before the final expiration date, say time $t$, the individual must choose whether to exercise the option immediately or to keep the option alive and make the exercise decision at the next exercise date. At time $t$, for any path $i$, where the utility from immediate exercise, $Z_{t, i}$, is larger than or equal to the expected utility of continuation conditional on the information available at time $t$ and path $i, \exp (-\beta \Delta t) E\left(J_{t+\Delta t} \mid \mathcal{F}_{t, i}\right)$, it is optimal to exercise the option. For any paths where the opposite holds, it is optimal to wait.

At time $t$ and path $i$, the value of immediate exercise, $Z_{t, i}$, is known to the individual 
but the value of waiting, $E\left(J_{t+\Delta t} \mid \mathcal{F}_{t, i}\right)$, is unknown. Note that the utility functions for retirement and annuitization are functions of two stochastic variables, the stock price, $S_{t}$, and the short-term interest rate, $r_{t}$. Let $\mathbf{S}_{t}=\left(S_{t, 1}, S_{t, 2, \ldots} S_{t, N}\right)^{\prime}, \mathbf{r}_{t}=\left(r_{t, 1}, r_{t, 2, \ldots} r_{t, N}\right)^{\prime}$, $\mathbf{X}_{t}=\left[\mathbf{S}_{t}, \mathbf{r}_{t}\right]$ and $t=n, \ldots, T$. Because $\left(\mathbf{X}_{t}\right)_{t=n, \ldots T}$ are $\left(\mathcal{F}_{t}\right)-$ Markov chains, for $t=n, \ldots T$, we have $E\left(J_{t+\Delta t} \mid \mathcal{F}_{t}\right)=E\left(J_{t+1} \mid \mathbf{X}_{t}\right)$, which allows us to use $\mathbf{X}_{t}$ to estimate the value of $E\left(J_{t+\Delta t} \mid \mathcal{F}_{t}\right)$. The conditional expectation at time $t$ and path $i,(-\beta \Delta t) E\left(J_{t+\Delta t} \mid \mathbf{X}_{t, i}\right)$, is approximated by regressing the vector of discounted value of continuation at time $t$, $\exp (-\beta \Delta t) \mathbf{J}_{t+\Delta t}$, where $\mathbf{J}_{t+\Delta t}=\left(J_{t+\Delta t, 1}, J_{t+\Delta t, 2}, \ldots J_{t+\Delta t, N}\right)^{\prime}$, on the simulated paths of a set of basis functions of relevant state variables at time $t, f_{k}\left(\mathbf{X}_{t}\right)$ where $1 \leq k \leq m, m$ denotes the number of basic functions, and $f_{k}(\cdot)$ 's are measurable real valued functions of $\mathbf{X}_{t}$. In this paper, $m$ equals to $2, f_{1}\left(\mathbf{X}_{t}\right)=\left[\mathbf{S}_{t}, \mathbf{r}_{t}\right]$ and $f_{2}\left(\mathbf{X}_{t}\right)$ includes the square terms of stock prices and interest rates and their cross term. The regression for estimating the expected value of waiting is

$$
\exp (-\beta \Delta t) J_{t+\Delta t}=B_{0}+B_{1} S_{t}+B_{2} r_{t}+B_{3} S_{t}^{2}+B_{4} r_{t}^{2}+B_{5} S_{t} r_{t}+\varepsilon, \varepsilon \sim \text { i.i.d.N }(0,1)
$$

where $B_{0}, B_{1}, B_{2}, B_{3}, B_{4}$ and $B_{5}$ are regression coefficients. The approximated conditional expectation at time $t$ and path $i,(-\beta \Delta t) \hat{E}^{m}\left(J_{t+\Delta t} \mid \mathbf{X}_{t, i}\right)$, is the fitted value of the regression, that is,

$$
(-\beta \Delta t) \hat{E}^{m}\left(J_{t+\Delta t} \mid \mathbf{X}_{t, i}\right)=B_{0}+B_{1} S_{t, i}+B_{2} r_{t, i}+B_{3} S_{t, i}^{2}+B_{4} r_{t, i}^{2}+B_{5} S_{t, i} r_{t, i}
$$

Clément, Lamberton and Protter (2002) analyzed the convergence properties of the LSM algorithm. They proved the strong convergence of $\hat{E}^{m}\left(J_{t+\Delta t} \mid \mathbf{X}_{t}\right)$ towards $E\left(J_{t+\Delta t} \mid \mathcal{F}_{t}\right)$. A brief discussion of the proof is provided in Appendix B. The result of Clément, Lamberton and Protter (2002) is confirmed by Egloff (2005) and Moreno and Navas (2003).

The individual will decide at time $t$ whether to exercise the option or not. For the paths where the value of immediate exercise, $Z_{t, i}$, is larger (smaller) than or equal to the estimated conditional expectation, $\exp (-\beta \Delta t) \hat{E}^{m}\left(J_{t+\Delta t} \mid \mathbf{X}_{t, i}\right)$, it is optimal to exercise the option (wait). Proceed these calculations and comparisons recursively backwards until the "purchase" date is reached. The optimal stopping time for each path is then decided by starting from the "purchase" date, moving along each path until the first stopping time. For each path, the first stopping time is the optimal exercise time for that path. Thus, there will be one and only one optimal stopping time for each path. 


\section{The Retirement Likelihood Measure}

Currently we are at time 0 , the stock price and interest rate at time 0 are known but the future prices are unknown. For each of the exercise dates, $1, \ldots T, N$ paths of stock prices and short-term interest rates are simulated. The probability estimated at time 0 of retiring before time $k, k$ could be any time between 1 and $T$, can be computed as follows.

Let $\tau_{r_{i}}^{*}$ denote the optimal retirement time for path $i, i=1,2, \ldots, N$. Let $H$ be a $N \times T$ matrix, where the rows correspond to the simulated paths and the columns correspond to time. The matrix $H$ records the optimal retirement decisions of the individual. If $H(i, j)=1, j$ is the optimal retirement time for path $i$, otherwise, $j$ is not the optimal retirement time for path $i$, that is,

$$
H(i, j)=\left\{\begin{array}{ll}
1 & \text { if } j=\tau_{r_{i}}^{*} \\
0 & \text { otherwise }
\end{array} .\right.
$$

By construction, there will be only one "1" in each row.

From the optimal decision matrix, $H$, we can derive an estimator of the probability

of retiring before and including time $k, k>0$. The notation, $P R_{0}^{\text {OptionModel }}$, denotes the retirement probability and

$$
P R_{0}^{\text {Option Model }}=\frac{1}{N} \sum_{j=1}^{k} \sum_{i=1}^{N} H(i, j) .
$$

At time 0 , the probability that the individual will retire before and including time $k$ is the percentage of the paths where the optimal retirement times occur no later than time $k$. This probability is referred to as the retirement likelihood measure.

\section{Summary of Section 4}

This section provides a solution methodology to the model described in Section 3. N paths are simulated for the future stock prices and interest rates. It is assumed that the retirement option can only be exercised and considered at a finite number of discrete times. At each path and for each possible retirement time, the optimal annuitization time and the optimal DC benefit are computed using the LSM algorithm. After that, the LSM algorithm is applied again to find the optimal retirement time in each path. The percentage of the paths where the optimal retirement time occurs before and including time $k$ is considered as an estimator of an individual's actual probability of retiring before and including time $k$. 


\section{Application to the Retirement Decision in the U.K.}

A forward-looking retirement likelihood measure was developed in Section 3 and 4. In this section, this likelihood measure will be tested empirically. This empirical investigation is based on data from the English Longitudinal Study of Ageing (ELSA).

\section{Data}

ELSA is a biannual panel survey among those aged 50 and over (and their younger partners) living in private households in England. The field work for ELSA wave 1 is conducted in 2002 -3 and for wave 2 in 2004 -5. There are 12,100 individuals interviewed in wave 1. 1,659 individuals are employed full time (not less than 30 hours per week) and are interviewed again in wave 2. Among them, 518 persons participate in DC plans and provides complete information about their DC accounts. The sample consists of these 518 individuals. Detailed information about the sample selection is given in table 1 .

[Please Insert Table 1 Here]

In this sample, 29 persons retired by the wave 2 interviews of ELSA. None of the 29 persons report that their main reason of retirement is due to the sickness of themselves or their family members. $69.5 \%$ of the individuals are contracted out which means that they cannot get retirement income from the second pillar state pensions (SERPS and S2P). In addition to the DC schemes, $31.27 \%$ of the individuals in the sample also have past DB plans and $11 \%$ of the individuals have current DB plans.

Our sample consists of 374 men and 144 women. $18.3 \%$ of the individuals have higher education or equivalent degrees. $30.5 \%$ of them didn't receive high school education. The summary statistics of the DC plan participants' age, gross income, DC wealth, asset income, benefit income, gross household wealth and debt are presented in table 2. The average age of the sample members is 55 . The average annual gross income is about $£ 24,400$ and the average DC wealth is $£ 33,122$. Overall, the size of the average DC plan is small compared with the gross income. The small size could be caused by the short contribution records and the contributions to parallel pension plans, for example, DB plans and SERPS. DC pension plans started widely in the U.K. in the 1990's, which means that the individuals in our sample started to contribute to the DC plan in their 40's. Asset income, benefit income, gross household wealth excluding the primary housing and debt are at household level. Asset income consists of interest income, dividend income and the rent from second house, etc. Benefit income refers to state benefits, for example, 
Minimum Income Guarantee (MIG), Child Benefit and Disable Benefit. Gross household wealth is the household's overall wealth excluding the house where they live.

[Please Insert Table 2 Here]

The short rate, the bond yield and stock index used in this paper are the U.K. 3month Treasury Bill rate, the U.K. 10-Year Government Bond yield and the FTSE All Share Index obtained from Datastream covering the period from Jan. 1984 to Dec. 2002 on quarterly basis. The summary statistics for these variables are provided in table 3 . The mean of the yield on the 10-year zero-coupon U.K. government bond is on average $8.22 \%$. The mean of the return of stock indices is $9.55 \%$. The mean of the short rate is $8.13 \%$ which is very high compared with the 10-year zero-coupon yield and the return on stock index.

\section{[Please Insert Table 3 Here]}

I use the Euler-Maruyama method to discretize diffusion processes of the short rate, stock index and bond price. The parameters of these diffusion processes are estimated from the U.K. data discussed above on quarterly frequency. The estimation method is introduced briefly in Appendix C. The estimation results are as follows, $\kappa_{r}=0.0232$, $\bar{r}=0.0129, \sigma_{r}=0.0019, \lambda_{s}=0.0367, \sigma_{s}=0.0911$ and $\lambda_{r}=-0.1117$.

\section{Projected Annual Incomes}

Information on past and future gross incomes is necessary to calculate the state pension and the DB pension income. The past and future gross income is projected based on the following variables: a gender dummy, experience which is defined as current age less the age the individual started to work divided by 10, dummies for education degrees and years of schooling. The (log) current gross annual income is regressed on the above mentioned variables and the square term of experience. The sample for testing the retirement likelihood measure consists of 518 individuals who work full time and have DC plans with complete information. But this analysis is based on the 1659 individuals who are working full time as reported at wave 1 interviews in order to make the projection more precise. The regression results are presented in table 4 .

[Please Insert Table 4 Here] 
The regression results show that female workers earn significantly less than male workers. Individuals with high education degree (higher education degree or equivalent) earn significantly more than individuals with low (lower than high school degree) and medium education (high school degree) degrees. Income also increases with years of schooling. Experience and its square term have correct signs but they are both insignificant which could due to the fact that the individuals in the sample are of similar age.

In this paper the inflation rate, $\pi$, is assumed to be constant at $2 \%$ level. The projected past or future labor incomes for individual $i, Y_{\text {projected }}$, is

$$
Y_{\text {projected }, i}=E Y(\theta)_{i} \exp \left(\pi\left(\theta-F_{i}\right)\right)
$$

where $F_{i}$ is the individual $i$ 's current age, $\theta$ stands for individual $i$ 's future age, $\theta>F_{i}$, or past age, $\theta<F_{i}$, and $E Y(\theta)_{i}$ denote the projected labor income of individual $i$ at wave 1 interviews if he is $\theta$ years old at that time which is derived from the regression reported in table 4 .

\section{BSP and SERPS}

The amount of state pension the individuals can receive depends on, among others, whether they are contracted out or in and how long they have contributed to the state pension. The individual cannot receive their state pension until his State Pension Age is reached. If the individual delays receiving the state pension, the amount of pension is increased, at present, by approximately 7.5 per cent per year of delay in return. The maximum reward for deferment is 37 per cent, which is achieved by deferring for five years.

For the individuals who contracted out (in) in the wave 1, I assume that they contracted out (in) throughout their working life. Before 2002, the second pillar state pension is called SERPS. After 2002, the SERPS is replaced by S2P. But since S2P is only introduced in 2002, the individuals' contribution records to S2P are very short. Therefore, this reform does not have big impact on the individuals' pension income at 2004. Thus, in this paper, this reform is ignored. Department of Work and Pensions (2005) gives a very detailed description about the calculation of BSP and SERPS income which is adopted for the calculation of state pension in this paper. 


\section{The Estimated Retirement Probability}

It is assumed that the interviews of wave 1 are conducted at the end of 2002 and the interviews of wave 2 are conducted at the end of 2004. For the individuals who are reported to be retired at wave 2 interviews, the exact retirement years are not known. Based on the information available at wave 1 interviews, the probabilities of retiring by wave 2 interviews, $P R_{2002}^{\text {Option Model }}$, are estimated for every individuals in the sample from eq. (20).

I assume that during 2003 and 2004, at the beginning of each year the individual has a chance to consider retirement. The FTSE All Share Index at the end of 2002, $S_{0}$, is 1893.73. The 3 -month T-Bill rate at that time is $3.87 \%$. The stock prices and bond prices for the years 2003 and 2004 are simulated from the diffusion processes (3) and (6). 2000 paths for future stock and bond prices are simulated. The subjective discount factor, $\beta$, is set to 0.02 , the risk aversion parameter, $\gamma$, is 5 , and the preference for leisure, $K$, equals to 1.5 in specification 1 . In specification 2 , for the individuals with DC wealth less than $£ 150,000, K$ equals to $\left(\frac{F}{55}\right)^{5}$ and for the individuals with DC wealth larger than $£ 150,000, K$ equals to $0.9\left(\frac{F}{55}\right)^{5}$. Since there are only 21 individuals with DC wealth larger than $£ 150,000$, this adjustment will not have a big impact on the overall results of the option model. $70 \%$ of the portfolio assets are stocks and $30 \%$ are bonds, that is, $\alpha=0.7$. The load factor in the annuity price calculation (8) is assumed to be 0.2 . The mortality rates are obtained from the U.K. Government Actuary's Department (GAD). The maximum age an individuals can live is assumed to be 100 .

Table 5 reports actual and average predicted percentage of the individuals who retire during 2003 and 2004 for the whole sample (518 individuals) and two subsamples. Subsample 1 consists of the individuals who retired at wave 2 and Subsample 2 consists of the individuals who were not yet retired at wave 2 . The actual percentage of retirement is $5.6 \%$. The predicted percentage of retirement is $3.91 \%$ for specification 1 and $3.29 \%$ for specification 2. The predicted percentage of retirement for the subsample 1 is $11.93 \%$ for specification 1 and $19.64 \%$ for specification 2 . For subsample 2, the predicted percentage of retirement is $3.44 \%$ of specification 1 and $2.32 \%$ for specification 2 .

\section{[Please Insert Table 5 Here]}

\section{The Proxy of Retirement Incentive}

In order to check whether the retirement likelihood measure, $P R_{2002}^{\text {OptionModel }}$, is significant in explaining and predicting the retirement decision making in reality, the retirement 
likelihood measure is treated as a proxy for retirement incentives. A Probit analysis is applied to test the significance of this proxy. The dependent variable is the sample individuals' retirement decisions reported at wave 2 interviews which takes value 1 if the individual is reported to be retired and 0 if not. The variables, Asset Income (AI), Benefit Income (BI), Gross Household Wealth (GH) and Debt, which are not used for calculating $P R_{2002}^{\text {OptionModel }}$ are also included in the analysis. The results are presented in table 6. For both leisure parameter specifications, the proxy of retirement incentives, $P R_{2002}^{\text {Option Model }}$, is positive and significant at $5 \%$ level no matter whether the other four variables are included or not. This analysis shows that the retirement likelihood has significant explanatory power in explaining and predicting the retirement decision in reality. It also means that financial incentives are important to the DC plan participants when they are making their retirement decision.

\section{[Please Insert Table 6 Here]}

\section{The Model Fit}

The model fit is analyzed by comparing the actual retirement probability at wave 2 interviews, the predicted retirement probability from the option model based on wave 1 interview information, $P R_{2002}^{\text {OptionModel }}$, and the predicted retirement probability from a Probit model, $P R_{2002}^{\mathrm{Pr} \text { obit }}$, where the regressors are variables such as, age, gender, education dummies, gross income and DC wealth, which are used for evaluating the retirement likelihood measure $P R_{2002}^{\text {Option Model }}$ and the dependent variable is the retirement decision at wave 2. The probability of retiring by wave 2 interviews computed from this Probit model is actually an in-sample prediction. By contrast, the prediction from the option model is out of sample.

[Please Insert Table 7 Here]

The probit regression reported in table 7 shows the impact of these variables on the individuals' retirement decision in the sample. The results are very intuitive. Older individuals are significantly more likely to retire than younger ones. Women are significantly more likely to retire than men. This is because in the U.K., the State Pension Age for women at 2002 is lower than that for men. Age and gender are significant at $5 \%$ level. DC wealth, gross income and education dummies have expected signs, but they are insignificant. From the Probit model in table 7, for each individual we can compute the (in-sample) probability of retiring by wave 2 interviews, $P R_{2002}^{\mathrm{Pr} o b i t}$. 
As in Stock and Wise (1990), I divide the sample into several age groups and then compare the actual retirement ratio in each age group with the predictions from the option model, $P R_{2002}^{\text {Option Model }}$, and from the Probit model, $P R_{2002}^{\text {Pr obit }}$. The results are shown in table 8 and figure 1. It can be seen from figure 1, that the actual retirement probability increases with age. The predictions from the option model catches this trend very well especially the one from specification 2. The correlations between the option model probabilities and the actual retirement probabilities are 0.92 for model specification $1(K=1.5)$ and 0.96 for model specification $2\left(K=\left(\frac{F}{55}\right)^{5}\right)$. The correlation between the (in-sample) Probit model probabilities and the actual probabilities is 0.94 . Furthermore, the option model probabilities from model specification 2 have roughly the same Mean Square Errors (MSEs) as those from the Probit analysis. The MSEs of these two predictions are almost zero. The MSE for option model specification 1 is $1 \%$ larger.

[Please Insert Table 8 and Figure 1 Here]

The sample was also divided by the DC wealth level. Level 1 includes the individuals with DC wealth smaller than $£ 5,000$. Level 2 includes individuals with DC wealth larger than $£ 5,000$ but smaller than $£ 10,000$ and so on until level 7 which is the highest level and includes the individuals with DC wealth larger than or equal to $£ 150,000$. The results are reported in table 9 and figure 2. Overall, the actual retirement probability is increasing with the DC wealth level. The correlation coefficient between the actual retirement ratio (column 2 in table 9 ) and the predicted retirement ratio from the Probit model is 0.78 . The correlation coefficient between the actual retirement ratio and the predicted retirement ratios from the option models are about 0.48 for specification 1 and 0.67 for specification 2. The MSEs of the Probit model and option model prediction 2 are close to 0 . The MSE of option model specification 1 is $2 \%$ larger.

[Please Insert Table 9 and Figure 2 Here]

Generally speaking, the performance of the option model, especially using the model specification where the leisure parameter is age dependent, in terms of correlations with the actual retirement probabilities and Mean Square Errors, are comparable to the performance of the in-sample Probit predictions. 


\section{Summary of Section 5}

Section 5 provides an empirical analysis to the retirement likelihood measure. ELSA data is adopted for this analysis. For each individual in the sample, the probability that he will retire before wave 2 interviews is evaluated based on the information available at wave 1 interviews. Model predictions are compared with actual retirement decisions and in-sample predictions from a Probit model where age, gender, DC wealth, gross income and education levels are used to explain the retirement decision by wave 2 interviews. The performances of option model predictions are comparable to the performances of the in-sample Probit predictions.

\section{Conclusions}

This paper analyzed the retirement and annuitization timing decisions of DC pension plan members. This paper first developed a retirement likelihood which takes into account the optimal annuitization timing decision and then tested it empirically. The retirement likelihood measure describes the probability that an individual will retire within the next years. This measure is applied to ELSA data. Based on information available at ELSA wave 1 interviews, for each individual in the sample, the likelihood of retirement before wave 2 interviews are computed.

The result of the Probit analysis, where the retirement likelihood measure is treated as a proxy for retirement incentive, show that it is positive and significant at $5 \%$ level in explaining the future retirement decision. The retirement likelihood measure is then compared with the actual retirement decisions and the in-sample predictions from a Probit regression which uses age, gender, education and DC wealth as explanatory variables. The performance of the retirement likelihood measure is comparable to the performance of the Probit regression, even though the predictions from the option model are out of sample while the predictions from the Probit regression are in sample.

It can be concluded that the retirement likelihood measure which takes into account the optimal annuitization timing decision has strong predictive power for the actual retirement timing decisions. This result suggest that in reality at least some individuals recognize the value of the freedom in choosing the annuitization time and take it into account when making their retirement decisions. 


\section{References}

Alistair, B., D. Harrison and D. Blake, (2007), Dealing with the reluctant investor Innovation and governance in DC pension investment, Pension - Institute Report for policymakers, employers, trustees, insurance companies, asset managers, consultants and financial advisers.

Blake, D. (2003), The U.K. pension system: Key issues. Pension - Institute Cass Business School Working Paper, wp0107.

Choi, K., and G. Shim, (2006), Disutility, optimal retirement, and portfolio selection, Mathematical Finance, 16(2), 443-467.

Clark, T. and C. Emmerson, (2003), Privatizing provision and attacking poverty? The direction of U.K. Pension policy under new Labour. Journal of Pension Economics and Finance, 2, 67-89.

Clement, E., L. Damien and P. Protter, (2002), An analysis of a least squares regression method for American option pricing, Finance and Stochastics, 6(4), 449-471.

Cocco, J. and P. Lopes, (2004), Defined benefit or defined contribution? An empirical study of pension choices, UBS PRP Discussion paper 26.

Coile, C. and J. Gruber, (2000), Social security incentive for retirement, NBER working paper 7651 .

Coronado, J., and M. Perozek, (2003), Wealth effects and the consumption of leisure: retirement decisions during the stock market boom of the 1990s, The Federal Reserve Board Finance and Economics Discussion Series 2003-23.

Department of Work and Pension, 2005, A guide to the state pension, NP46.

Egloff, D. (2005), Monte Carlo algorithm for optimal stopping and statistical learning, The Annals of Applied Probability, 15 (2), 1396-1432.

Farhi, E. and S. Panageas, (2007), Saving and investing for early retirement: A theoretical analysis, Journal of Financial Economics, 83(1), 87-121.

FDIC, (2006), The shift away from defined benefit plans, FDIC Outlook.

Friedberg, L. and A. Webb, (2003), Retirement and the evolution of pension structure, NBER working paper 9999. 
Gustman, A. and T. Steinmeier, (2002), Retirement and the stock market bubble, NBER Working Paper 9404.

Lachance, M., (2003), Optimal investment behavior as retirement looms, University of Pennsylvania Working Paper.

Liu, J. and E. Neis, (2002), Endogenous retirement and portfolio choice, UCLA Working Paper.

Longstaff, F. and E. Schwartz, (2001), Valuing American options by simulations: A simple least - square approach. The Review of Financial Studies, 14(1), 113-147.

Milevsky, M. and V. Young, (2002), Optimal asset allocation and the real Option to delay annuitization: It's not now-or-never, Pension Institute Discussion Paper PI-0211.

Milevsky, M. and V. Young, (2007), The timing of annuitization: Investment dominance and mortality risk, Insurance:Mathematics and Economics, 40, 135-144.

Mitchell, O., J. Poterba, M. Warshawsky, and J. Brown, (1999), New evidence on money's worth of individual annuities, American Economic Review, 89, 1299-1318.

Moreno, M. and J. Navas, (2003), On the robustness of Least-Squares Monte Carlo (LSM) for pricing American derivatives, Review of Derivatives Research, 6, 107-128.

Munk, C., C. Sorensen and T. Vinther, (2002), Dynamic asset allocation under meanreverting returns, stochastic interest rates and inflation uncertainty - Are popular recommendations consistent with rational behavior?, Southern Denmark University Working Paper.

Peskir, G. and A. Shiryaev, (2006), Optimal stopping and free-boundary problems, Basel : Birkhäuser, ISBN: 3-7643-2419-8.

Rust, J., (1987), Optimal replacement of GMC bus engines: an empirical model of Harold Zurcher, Econometrica, 55(5), 999-1033.

Ross, D. and L. Wills, (2002), The shift from defined benefit to defined contribution retirement plans and the provisioning of retirement savings, Pension Institute Discussion Paper PI-0210.

Samwick, A., (1998), New evidence on pensions, social security, and the timing of retirement, Journal of Public Economics, 70(2), 207-236. 
Samwick, A. and J. Skinner, (1998), How will defined contribution plans affect retirement income?, NBER Working Paper 6645.

Stock, J. and D. Wise, (1990), Pensions, the option value of work, and retirement. Econometrica, 58 (5), 1151-1180.

Sundaresan, S. and F. Zapatero, (1997), Valuation, optimal asset allocation and retirement incentives of pension plans. The Review of Financial Studies, 10 (3), 631-660.

Yaari, M., (1965), Uncertainty lifetime, life insurance and the theory of the consumer, Review of Economics Studies, 32, 137-150. 


\section{Appendix A}

We have

$$
\begin{aligned}
& J_{n} \geq E\left(Z_{\tau} \mid \mathcal{F}_{n}\right) \text { for each } \tau \in(n, T), \\
& J_{n}=E\left(Z_{\tau_{n}^{T}} \mid \mathcal{F}_{n}\right) .
\end{aligned}
$$

Taking expectation in (21), we find that $E J_{n} \geq E\left(Z_{\tau} \mid \mathcal{F}_{n}\right)$ for all $\tau \in(n, T)$ and hence by taking the supremum over all $\tau \in(n, T)$ we see that $E J_{n} \geq V_{n}$. On the other hand, taking the expectation in (22), we get $E J_{n}=E\left(Z_{\tau_{n}^{T}} \mid \mathcal{F}_{n}\right)$. Since $\tau_{n} \in(n, T)$ and (15), it holds that $E\left(Z_{\tau_{n}^{T}} \mid \mathcal{F}_{n}\right) \leq V_{n}$ and therefore, $E J_{n} \leq V_{n}$. The two inequalities give the equality $V_{n}=E J_{n}$, and since $E J_{n}=E\left(Z_{\tau_{n}^{T}} \mid \mathcal{F}_{n}\right)$, we see $V_{n}=E\left(Z_{\tau_{n}^{T}} \mid \mathcal{F}_{n}\right)$ implying that $\tau_{n}$ is the optimal stopping time to the problem (15).

\section{Appendix B}

The LSM algorithm involves two types of approximations. Approximation one: replace the conditional expectations in the dynamic programming principle, $E\left(J_{t+\Delta t} \mid \mathcal{F}_{t}\right)$, by an orthogonal projection on a finite set of basic functions, $f_{k}\left(X_{t}\right), 1 \leq k \leq m$. This approximation is denoted by

$$
E^{m}\left(J_{t+\Delta t} \mid \mathcal{F}_{t}\right)=\sum_{k=1}^{m} \beta_{k} \times f_{k}\left(X_{t}\right),
$$

where $\beta$ coefficients are constants. They proved that as $m$ goes to infinity, $E^{m}\left(J_{t+\Delta t} \mid \mathcal{F}_{t}\right)$ converges to $E\left(J_{t+\Delta t} \mid \mathcal{F}_{t}\right)$.

Approximation two: use Monte-Carlo simulations and least squares regression to estimate $E^{m}\left(J_{t+\Delta t} \mid \mathcal{F}_{t}\right)$. The regression is described in section 3 . The fitted value of the regression is denoted by $\hat{E}^{m}\left(J_{t+\Delta t} \mid \mathcal{F}_{t}\right)$. Clément, et. al (2002) showed that as the number of simulated paths, $N$, goes to infinity, the values of $\hat{E}^{m}\left(J_{t+\Delta t} \mid \mathcal{F}_{t}\right)$ converges towards $E^{m}\left(J_{t+\Delta t} \mid \mathcal{F}_{t}\right)$. Clément, et. al (2002) proved the almost sure convergence of the complete algorithm under very general conditions.

Clément, et. al (2002) analyzed the convergence of the LSM algorithm assuming a linear relationship between $E^{m}\left(J_{t+\Delta t} \mid \mathcal{F}_{t}\right)$ and $f_{k}\left(X_{t}\right)$. Egloff (2005) analyzed convergence of the LSM algorithm without this assumption. His result strengthened and extended the result obtained by Clément, et al (2002). 


\section{Appendix C: The Parameter Estimation}

In this subsection, the parameters of the diffusion processes, (2), (3) and (6), will be estimated. The Euler-Maruyama method is used to derive the discrete-time approximations of these diffusion processes. For the short term interest rate, the discrete-time approximation is

$$
\begin{aligned}
r_{t+\Delta t}-r_{t} & =\kappa_{r}\left(\bar{r}-r_{t}\right) \Delta t+u_{r, t+\Delta t}, \\
r_{t+\Delta t} & =\alpha+\beta_{r} r_{t}+u_{r, t+\Delta t},
\end{aligned}
$$

where the error term, $u_{r, t+\Delta t}=\sigma_{r} \Delta Z_{1}$ with $\Delta Z_{1}=Z_{1, t+\Delta t}-Z_{1, t}$, is normal distributed with

$$
\begin{aligned}
& E_{t}\left(u_{r, t+\Delta t}\right)=0, \\
& E_{t}\left(u_{r, t+\Delta t}^{2}\right)=\sigma_{r}^{2} \Delta t,
\end{aligned}
$$

$\alpha=\kappa_{r} \bar{r} \Delta t$ and $\beta_{r}=1-\kappa_{r} \Delta t$. The discrete-time approximation of the stock index is

$$
S_{t+\Delta t}-S_{t}=S_{t}\left(r_{t}+\lambda_{s} \sigma_{s}\right) \Delta t+u_{s, t+\Delta t}
$$

where the error term, $u_{s, t+\Delta t}=\sigma_{s} S_{t} \Delta Z_{2}$ with $\Delta Z_{2}=Z_{2, t+\Delta t}-Z_{2, t}$, has the properties

$$
\begin{aligned}
& E_{t}\left(u_{s, t+1}\right)=0 \\
& E_{t}\left(u_{s, t+1}^{2}\right)=\sigma_{s}^{2} S_{t}^{2} \Delta t,
\end{aligned}
$$

and $\beta_{s}=1+\lambda_{s} \sigma_{s} \Delta t$. The distribution of the excess return on stock index can be approximated by a normal distribution with mean $\lambda_{s} \sigma_{s} \Delta t$ and variance $\sigma_{s}^{2} \Delta t$. For this estimation, $\Delta t$ is taken to be 1 , referring to 1 quarter of a year.

The estimation of the $\mathrm{AR}(1)$ model (24) is presented in table 10. The $\mathrm{AR}(1)$ term of the short rate, $\beta_{r}$, is significant at $1 \%$ level. From the estimation reported in table 3 , we can get $\kappa_{r}=0.0232$ and $\bar{r}=0.0129$. The volatility of the short rate, $\sigma_{r}$, is derived from the residuals of the two $\operatorname{AR}(1)$ process and $\sigma_{r}=0.0019$. The price of risk for stock index and the volatility of stock index are estimated from the distribution of excess return of stock index. We have $\lambda_{s}=0.0367$ and $\sigma_{s}=0.0911$.

Let the yield of a 10-year zero-coupon government bond derived from Vasicek model be $\hat{Y}_{t}$, which is a function of $\lambda_{r}$ and let $Y_{t}$ stands for the yield in the data sample. $\lambda_{r}$ is 
estimated by minimizing the objective function, $F\left(\lambda_{r}\right)$,

$$
F\left(\lambda_{r}\right)=\frac{1}{T} \sum_{t=1}^{T}\left(\hat{Y}_{t}\left(\lambda_{r}\right)-Y_{t}\right)^{2}
$$

The price of risk for short-term interest rate, $\lambda_{r}$, is -0.1117 . 


\section{Table 1 Sample Selection}

This table shows detailed information about the sample selection, including the reasons why individuals are removed from the sample and the number of individuals removed. Except reason (5), the other removal reasons are based on information reported at wave 1 interviews. There are 12,100 individuals participated in the ELSA wave 1 interviews. The sample in this paper consists of 518 individuals which DC pension plans.

\begin{tabular}{l|c}
\hline \multicolumn{1}{c|}{ Removal Reasons } & Number of Individuals Removed \\
\hline (1) Younger than 50 or older than 90 & 673 \\
(2) Not employed & 8375 \\
(3) Work less than 30 hours per week & 873 \\
(4) Incomplete information about & 148 \\
education & \\
(5) Do not participate in wave 2 & 372 \\
interviews & 1131 \\
(6) Do not have DC pension plan & 10 \\
(7) The size of the DC scheme is not \\
known
\end{tabular}


Table 2 Summary Statistics for the DC Plan Participants

\begin{tabular}{l|rc}
\hline \hline & Mean & Standard Deviation \\
\hline \hline Current Age & 55.24 & 3.55 \\
Gross Annual Income (in $£$ ) & $24,443.95$ & $22,955.85$ \\
DC Wealth (in $£$ ) & $33,121.53$ & $49,371.40$ \\
& & $7,926.75$ \\
Asset Income (in $£$ ) & $1,635.14$ & $1,188.48$ \\
Benefit Income (in $£$ ) & 366.16 & $20,0977.47$ \\
Household Wealth excl. & & $7,639.93$ \\
Primary House (in $£$ ) & $3,611.31$ & \\
Debt (in $£$ ) & & \\
\hline \hline
\end{tabular}

Table 3 Summary Statistics for the Short-Term Interest Rate, 10 - Year Government Bond Yield and the Stock Return in the UK 1984 - 2002

\begin{tabular}{l|cc}
\hline \hline & Mean & Standard Deviation \\
\hline \hline 3-Month UK T-Bill rate & $8.13 \%$ & $1.42 \%$ \\
$\begin{array}{l}\text { 10 - Year Zero - Coupon } \\
\text { UK Government Bond } \\
\text { Yield }\end{array}$ & $8.22 \%$ & $1.03 \%$ \\
$\begin{array}{l}\text { Annual Return of FTSE All } \\
\text { Share Index }\end{array}$ & $9.55 \%$ & $18.32 \%$ \\
\hline \hline
\end{tabular}




\section{Table 4 Projection of Labor Income}

The past and future gross incomes are projected based on the following variables: a gender dummy, experience which is defined as current age minus the age the individual started to work divided by 10 , dummies for education degrees and years of schooling. High Education is a dummy, which equals to 1 if the individual has higher education or equivalent degree. Low Education is a dummy, which equals to 1 if the individual has educational degree lower than high school. The dependent variable is the log of the current gross annual income.

\begin{tabular}{l|c}
\hline \hline Parameters & Values \\
\hline \hline Constant & $9.5517^{* *}$ \\
Female & $-0.3806^{* *}$ \\
Experience & 0.0818 \\
Experience ${ }^{2}$ & $-0.028^{* *}$ \\
Low Education & $-0.2094^{* *}$ \\
High Education & $0.3424^{* *}$ \\
Years of Schooling & $0.0519^{* *}$ \\
\hline \hline
\end{tabular}

${ }^{* *}$ means significance at $5 \%$ level. 
Table 5 Likelihood of Retiring During 2003 and 2004 Measured at 2002

The estimated retirement probability evaluated at the end of $2002, P R_{2002}^{\text {OptionModel }}$, is an indicator measuring how likely the individuals will retire between 2003 and 2004. $P R_{2002}^{\text {optionModel }}$ is evaluated with the method discussed in section 4. This table reports the mean of the estimated retirement probability for the whole sample, the subsample consisting of individuals retired at wave 2, and the subsample consisting of individuals who are not retired at wave 2. There are two specifications for parameter $\mathrm{K}$. In model specification 1, the disutility of work parameter $\mathrm{K}$ is a constant which equals to 1.5. In model specification $2, K=(F / 55)^{5}$ for the individuals with DC wealth smaller than $£ 150,000$ and $\mathrm{K}=0.9 \times(\mathrm{F} / 55)^{5_{1}}$ for the individuals with $\mathrm{DC}$ wealth larger than or equals to $£ 150,000$.

\begin{tabular}{|c|c|c|c|}
\hline & \multirow{2}{*}{$\begin{array}{c}\text { Actual } \\
\text { Percentage of } \\
\text { Retirement }\end{array}$} & \multicolumn{2}{|c|}{$\begin{array}{l}\text { Predicted Retirement Probability } \\
\qquad P R_{2002}^{\text {OptionModel }}\end{array}$} \\
\hline & & $\mathrm{K}=1.5$ & $\mathrm{~K}=(\mathrm{F} / 55)^{5}$ \\
\hline Whole Sample & $5.60 \%$ & $3.91 \%$ & $3.29 \%$ \\
\hline $\begin{array}{l}\text { Subsample 1: } \\
\text { Retired }\end{array}$ & $100.00 \%$ & $11.93 \%$ & $19.64 \%$ \\
\hline $\begin{array}{l}\text { Subsample 2: Not } \\
\text { Retired }\end{array}$ & $0.00 \%$ & $3.44 \%$ & $2.32 \%$ \\
\hline
\end{tabular}




\section{Table 6 Retirement Likelihood Measure As a Proxy for Retirement Incentive}

This table reports the results of the Probit regression of $P R_{2002}^{\text {OptionModel }}$. The dependent variable equals to 1 when the individual is reported to be retired at wave 2 and 0 otherwise. Asset income (AI) consists of interest income, dividend income and the rent from second house, etc. Benefit income (BI) refers to the state benefits, for example, Minimum Income Guarantee (MIG), Child Benefit and Disable Benefit. Gross household wealth $(\mathrm{GH})$ is the household's overall wealth excluding the house where they live. There are two specifications for parameter K. In model specification 1, the disutility of work parameter $\mathrm{K}$ is a constant which equals to 1.5 . In model specification $2, \mathrm{~K}=(\mathrm{F} / 55)^{5}$ for the individuals with DC wealth smaller than $£ 150,000$ and $\mathrm{K}=0.9 \times(\mathrm{F} / 55)^{51}$ for the individuals with DC wealth larger than or equals to $£ 150,000$. Panels A and B report the results from specification 1 and 2, respectively. ${ }^{*}$ stands for significance at $10 \%$ level and ${ }^{* *}$ stands for significance at $5 \%$ level and ${ }^{* * *}$ stands for significance at $1 \%$ level.

\section{Panel A: Specification 1}

\begin{tabular}{l|cc}
\hline \hline & Submodel 1 & Submodel 2 \\
\hline Constant & $-1.6406^{* * * *}$ & $-1.6213^{* * * *}$ \\
& $(0.0947)$ & $(0.1146)$ \\
$P R_{2002}^{\text {Optionodel }}$ & $0.8123^{* * *}$ & $0.8508^{* *}$ \\
& $(0.3707)$ & $(0.3845)$ \\
Asset Income (AI) & & -0.0000 \\
& & $(0.0000)$ \\
Benefit Income (BI) & & 0.0000 \\
& & $(0.0001)$ \\
Gross Household Wealth excl. & & 0.0000 \\
Primary Housing (GH) & & $(0.0000)$ \\
Debt & & -0.0000 \\
\hline \hline
\end{tabular}


Panel B: Specification 2

\begin{tabular}{l|rc}
\hline \hline & Submodel 1 & Submodel 2 \\
\hline Constant & $-1.6930^{* * *}$ & $-1.6754^{* * *}$ \\
& $(0.0977)$ & $(0.1171)$ \\
$P R_{\text {2002 }}^{\text {OptionModel }}$ & $1.4361^{* *}$ & $1.4611^{* * *}$ \\
& $(0.3511)$ & $(0.3574)$ \\
Asset Income (AI) & & -0.0000 \\
& & $(0.0000)$ \\
Benefit Income (BI) & & 0.0000 \\
& & $(0.0001)$ \\
Gross Household Wealth & & 0.0000 \\
excl. Primary Housing & & $(0.0000)$ \\
GH) & & -0.0000 \\
Debt & & $(0.0000)$ \\
\hline \hline
\end{tabular}




\section{Table 7 Comparison Probit Regression}

This table reports the results of the Probit regression of age, gender and other variables related to individual retirement decisions. The dependent variable equals to 1 when the individual is reported to be retired at wave 2 and 0 otherwise. The gender dummy equals to 1 for woman and 0 for man. The high education dummy equals to 1 for the individuals with higher education degree or equivalent. The low education dummy equals to 1 for the individuals with degree lower than high school degree. stands for significance at $10 \%$ level and ${ }^{* *}$ stands for significance at $5 \%$ level and ${ }^{* * *}$ stands for significance at $1 \%$ level.

\begin{tabular}{l|c}
\hline \hline & Coefficients \\
\hline \multirow{2}{*}{ Constant } & $-11.0969^{* * *}$ \\
Age & $(1.6676)$ \\
& $0.1642^{* *}$ \\
Gender & $(0.0281)$ \\
& $0.5301^{* *}$ \\
High Education & $(0.2331)$ \\
& -0.5086 \\
Low Education & $(0.3671)$ \\
\multirow{2}{*}{ DC Wealth/1000 } & 0.0728 \\
& $(0.2242)$ \\
Gross Income/1000 & 0.0027 \\
& $(0.0021)$ \\
\hline \hline
\end{tabular}




\section{Table 8 Actual and Predicted Retirement Ratios By Age Groups}

This table shows the actual and predicted retirement ratios from the Probit model presented in table 7 and the option model. The actual percentage of retirement measures the percentage of individuals retired by the end of 2004 for each age group. $P R_{2002}^{\text {Probit }}$ is the prediction made from the Probit model described in table 7 and $P R_{2002}^{\text {OptionModel }}$ is the prediction from the option model described in section 4. In the option model, there are two specifications for the leisure parameter, K. In specification 1, the disutility of work parameter $\mathrm{K}$ is a constant which equals to 1.5 . In specification $2, \mathrm{~K}=(\mathrm{F} / 55)^{5}$ for the individuals with $\mathrm{DC}$ wealth smaller than $£ 150,000$ and $\mathrm{K}=0.9 \times(\mathrm{F} / 55)^{5}$ for the individuals with $\mathrm{DC}$ wealth larger than or equals to $£ 150,000$.

\begin{tabular}{|c|c|c|c|c|c|}
\hline \multirow[t]{2}{*}{ Age } & \multirow[t]{2}{*}{ No. of Obs } & \multirow{2}{*}{$\begin{array}{c}\text { Actual } \\
\text { Percentage of } \\
\text { Retirement } \\
P R_{2002}^{\text {Actual }}\end{array}$} & \multirow{2}{*}{$\begin{array}{l}\text { In-Sample } \\
\text { Predicted } \\
\text { Percentage of } \\
\text { Retirement } \\
\text { from Probit } \\
\text { Model } \\
P R_{2002}^{\text {Probit }}\end{array}$} & \multicolumn{2}{|c|}{$\begin{array}{c}\text { Predicted Percentage of } \\
\text { Retirement from Option } \\
\text { Model } \\
P R_{2002}^{\text {OptionModel }}\end{array}$} \\
\hline & & & & $\mathrm{K}=1.5$ & $\mathrm{~K}=\mathrm{k}_{0}(\mathrm{~F} / 55)^{\mathrm{k}}$ \\
\hline 50 & 29 & 0.00 & 0.00 & 0.00 & 0.00 \\
\hline 51 & 50 & 0.02 & 0.01 & 0.00 & 0.00 \\
\hline 52 & 53 & 0.02 & 0.01 & 0.04 & 0.00 \\
\hline 53 & 56 & 0.02 & 0.02 & 0.02 & 0.00 \\
\hline 54 & 59 & 0.02 & 0.02 & 0.02 & 0.00 \\
\hline 55 & 58 & 0.03 & 0.03 & 0.04 & 0.02 \\
\hline 56 & 50 & 0.00 & 0.04 & 0.02 & 0.00 \\
\hline 57 & 25 & 0.12 & 0.06 & 0.05 & 0.00 \\
\hline 58 & 36 & 0.08 & 0.07 & 0.07 & 0.02 \\
\hline 59 & 33 & 0.03 & 0.10 & 0.04 & 0.02 \\
\hline 60 & 21 & 0.05 & 0.12 & 0.05 & 0.06 \\
\hline 61 & 18 & 0.17 & 0.17 & 0.13 & 0.17 \\
\hline 62 & 12 & 0.25 & 0.22 & 0.09 & 0.17 \\
\hline$>=63$ & 18 & 0.50 & 0.33 & 0.20 & 0.45 \\
\hline \multicolumn{2}{|c|}{ Corr. Coef with Column 3} & & 0.94 & 0.92 & 0.96 \\
\hline \multicolumn{2}{|c|}{ Corr. Coef with Column 4} & & & 0.92 & 0.94 \\
\hline \multicolumn{2}{|c|}{ Mean Square Error } & & 0.00 & 0.01 & 0.00 \\
\hline
\end{tabular}




\section{Table 9 Actual and Predicted Retirement Ratio By DC Wealth Groups}

This table shows the actual and predicted retirement ratios from the Probit model and the option model. The actual percentage of retirement measures the percentage of individuals retired by the end of 2004 for each wealth group. $R_{2002}^{\text {Probit }}$ is the prediction made from the Probit model described in table 7 and $R_{2002}^{\text {Option }}$ odel is the prediction from the option model described in section 4.

\begin{tabular}{|c|c|c|c|c|c|c|}
\hline \multirow[t]{2}{*}{ Level } & \multirow[t]{2}{*}{$\begin{array}{c}\text { DC Wealth } \\
\text { Size }\end{array}$} & \multirow[t]{2}{*}{ No. of Obs } & \multirow{2}{*}{$\begin{array}{c}\text { Actual } \\
\text { Percentage } \\
\text { of } \\
\text { Retirement } \\
P R_{2002}^{\text {Actual }}\end{array}$} & \multirow{2}{*}{$\begin{array}{l}\text { Predicted } \\
\text { Percentage } \\
\text { of } \\
\text { Retirement } \\
\text { from Probit } \\
\text { Model } \\
P R_{2002}^{\text {Probit }}\end{array}$} & \multicolumn{2}{|c|}{$\begin{array}{c}\text { Predicted Percentage of } \\
\text { Retirement from Option } \\
\text { Model } \\
P R_{2002}^{\text {OptionModel }} \\
\end{array}$} \\
\hline & & & & & $\mathrm{K}=1.5$ & $\mathrm{~K}=\mathrm{k}_{0}(\mathrm{~F} / 55)^{\mathrm{k}_{1}}$ \\
\hline 1 & $<£ 5,000$ & 132 & 0.05 & 0.06 & 0.02 & 0.01 \\
\hline 2 & $\begin{array}{l}£ 5,000- \\
£ 10,000\end{array}$ & 70 & 0.04 & 0.05 & 0.00 & 0.01 \\
\hline 3 & $\begin{array}{c}£ 10,000- \\
£ 25,000\end{array}$ & 145 & 0.04 & 0.05 & 0.03 & 0.04 \\
\hline 4 & $\begin{array}{c}£ 25,000- \\
£ 50,000\end{array}$ & 56 & 0.07 & 0.05 & 0.00 & 0.00 \\
\hline 5 & $\begin{array}{l}£ 50,000- \\
£ 100,000\end{array}$ & 76 & 0.08 & 0.05 & 0.02 & 0.02 \\
\hline 6 & $\begin{array}{c}£ 100,000- \\
£ 150,000\end{array}$ & 17 & 0.12 & 0.10 & 0.11 & 0.14 \\
\hline 7 & $>=£ 150,000$ & 22 & 0.09 & 0.11 & 0.48 & 0.23 \\
\hline \multicolumn{3}{|c|}{ Corr. Coef with Column 4} & & 0.78 & 0.48 & 0.67 \\
\hline \multicolumn{3}{|c|}{ Corr. Coef with Column 5} & & & 0.85 & 0.97 \\
\hline \multicolumn{3}{|c|}{ Mean Square Error } & & 0.00 & 0.02 & 0.00 \\
\hline
\end{tabular}


Table 10 Estimation of AR(1) Processes for Stock Index and Short-Term Interest

\begin{tabular}{l|c}
\hline & Short-Term Interest Rates \\
\hline \hline$\alpha$ & 0.0003 \\
& $(0.0007)$ \\
$\beta_{\mathrm{r}}$ & $0.9768^{* * *}$ \\
& $(0.0319)$ \\
\hline \multirow{2}{*}{$\mathrm{R}^{2}$} & 0.9278 \\
\hline \hline
\end{tabular}

${ }^{* * * *}$ means significance at $1 \%$ level, ${ }^{* * *}$ means significance at $5 \%$ level and ${ }^{*}$ means significance at $10 \%$ level. 


\section{Figure 1 Actual and Predicted Retirement Ratios By Age Groups}

This figure shows the actual and predicted retirement ratios from the Probit model and the option model which are reported in table 8.

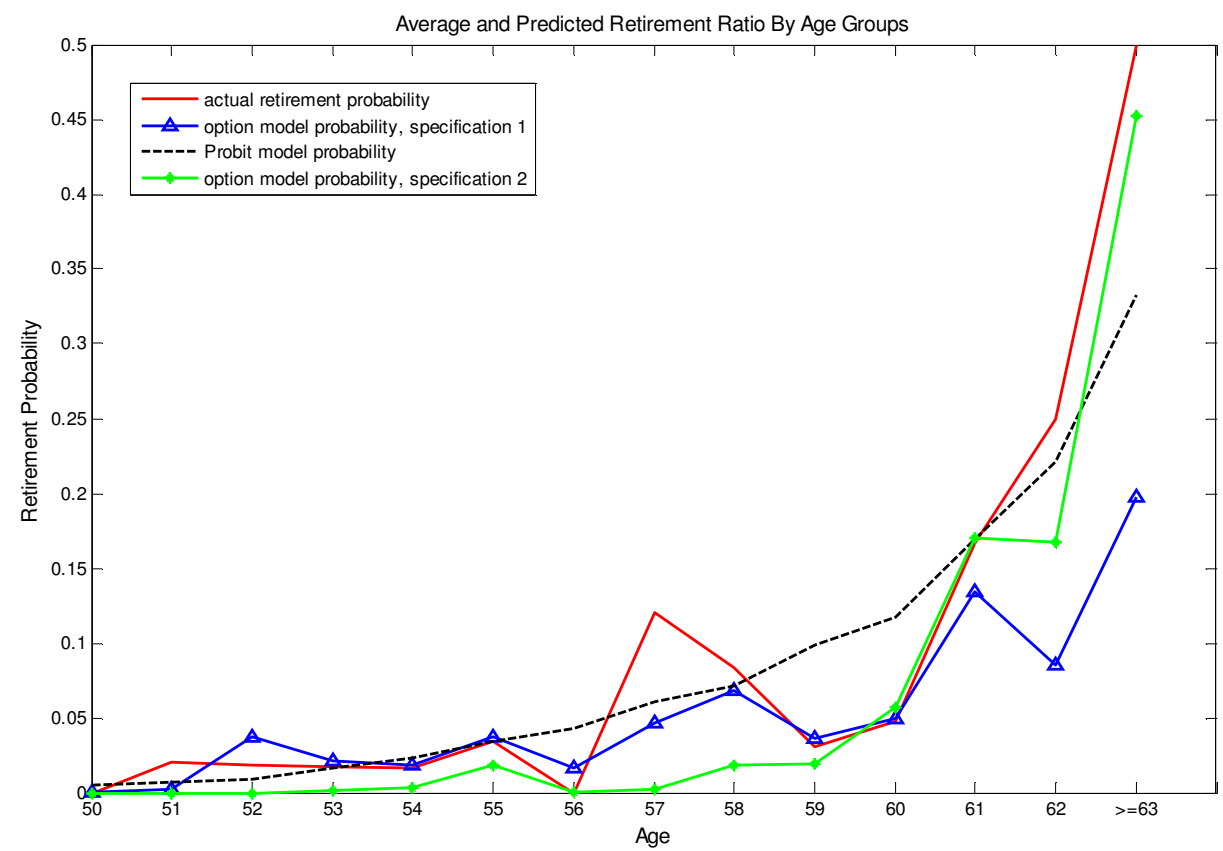




\section{Figure 2 The Actual and Predicted Retirement Ratios By DC Wealth Group}

This table shows the actual and predicted retirement ratios from the Probit model and the option model. The actual percentage of retirement measures the percentage of individuals retired by the end of 2004 for each wealth group. $R_{2002}^{\text {Probit }}$ is the prediction made from the Probit model described in table 7 and $R_{2002}^{\text {OptionModel }}$ is the prediction from the option model described in section 4 . Group 1 are the individuals with DC wealth less than $<£ 5,000$, Group 2 includes the individuals with DC wealth between $£ 5,000$ and $£ 10,000$, Group 3 includes the individuals with DC wealth between $£ 10,000$ and $£ 25,000$, Group 4 includes the individuals with DC wealth between $£ 25,000$ and $£ 50,000$, Group 5 includes the individuals with DC wealth between $£ 50,000$ and $£ 100,000$, Group 6 includes the individuals with DC wealth between $£ 100,000$ and $£ 150,000$, and Group 7 includes the individuals with DC wealth larger or equal to $£ 150,000$.

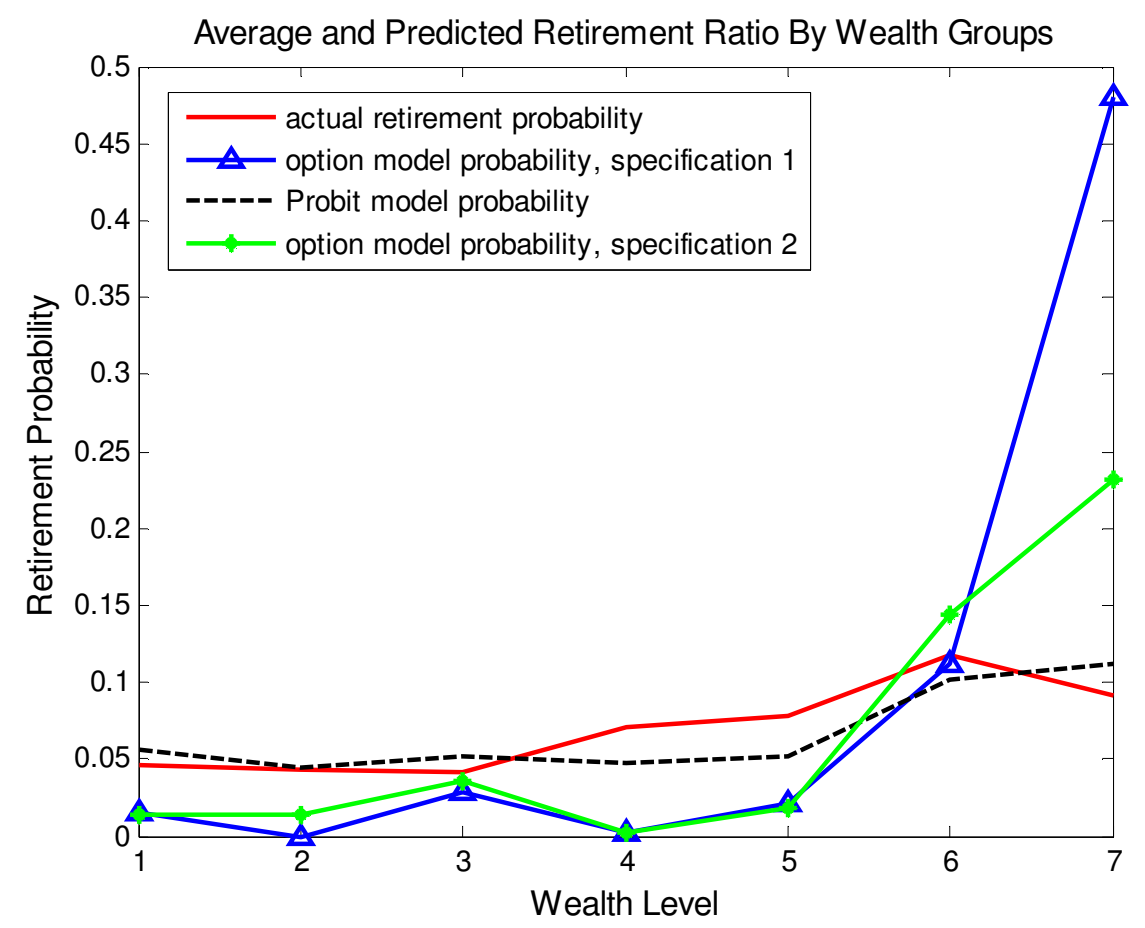

